\title{
An executive functioning perspective in neurofibromatosis type 1: from ADHD and autism spectrum disorder to research domains
}

\author{
Taylor F. Smith ${ }^{1}$ • Jessica A. Kaczorowski ${ }^{1}$ - Maria T. Acosta ${ }^{2,3}$ (D)
}

\begin{abstract}
Purpose Neurofibromatosis type 1 (NF1) is a rare monogenic disorder associated with executive function (EF) deficits and heightened risk for attention-deficit/hyperactivity disorder (ADHD) and autism spectrum disorder (ASD). The goal of this paper is to understand how EFs provide a common foundation to understand vulnerabilities for ADHD and ASD within NF1.

Methods A literature review and synthesis was conducted.

Results EF difficulties in working memory, inhibitory control, cognitive flexibility, and planning are evident in NF1, ADHD, and ASD. However, relatively little is known about the heterogeneity of EFs and ADHD and ASD outcomes in NF1. Assessment of ADHD and ASD in NF1 is based on behavioral symptoms without understanding neurobiological contributions. Recent efforts are promoting the use of dimensional and multidisciplinary methods to better understand normal and abnormal behavior, including integrating information from genetics to self-report measures.

Conclusion NF1 is a monogenic disease with well-developed molecular and phenotypic research as well as complementary animal models. NF1 presents an excellent opportunity to advance our understanding of the neurobiological impact of known pathogenic variation in normal and abnormal neural pathways implicated in human psychopathology. EFs are core features of NF1, ADHD, and ASD, and these neurodevelopmental outcomes are highly prevalent in NF1. We propose a multilevel approach for understanding EFs in patients with NF1. This is essential to advance targeted interventions for NF1 patients and to advance the exciting field of research in this condition.
\end{abstract}

Keywords Neurofibromatosis $1 \cdot$ Executive functions $\cdot$ Attention-deficit/hyperactivity disorder $\cdot$ Autism spectrum disorder

\section{Introduction to neurofibromatosis 1 and related neurodevelopmental outcomes}

Neurofibromatosis 1 (or NF1) is a neurocutaneous disorder affecting 1 in 2700 live births [1]. Diagnostic criteria for NF1 include at least two of the following: 6 or more caféau-lait macules, two or more neurofibromas or one plexiform

Maria T. Acosta

acostam@mail.nih.gov

1 Department of Psychology and Child Development, California Polytechnic State University, San Luis Obispo, San Luis Obispo, CA, USA

2 Office of the Clinical Director and Medical Genetic Branch, National Human Genome Research Institute, National Institutes of Health, Bethesda, MD, USA

3 National Human Genome Research Institute, National Institutes of Health, Building 10, Room 3 I485 NE, Bethesda, MD 20892-3717, USA neurofibroma, freckling in axillary region, optic glioma, multiple lisch nodules, distinctive osseous lesion, or a first-degree relative with NF1 [2] (see [3] for a review of the clinical phenotype). NF1 is caused by a pathogenic $N F 1$ heterozygous variant. The $N F 1$ gene encodes for neurofibromin which negatively regulates the Ras pathway [3, 4].

NF1 research has grown exponentially in the last 20 years thanks to the common efforts of researchers, funding agencies, private philanthropy, and advocacy groups. The result is extensive new knowledge into the neurobiology of the disease and further characterization of the NF1 phenotype. The result, a recent FDA approved treatment [5] for plexiform neurofibroma, brings hope for many patients and families. In addition, new animal models $[6,7]$ complement existing well-established NF1 models to increase opportunities for research and development of interventions. Despite this progress, molecularand disease-targeted interventions for cognitive deficits remain elusive. 
NF 1 increases risk for cognitive deficits and neurodevelopmental disorders [8-11]. Research indicates a characteristic "downward shift" in intellectual functioning, where individuals with NF1 score approximately 1 standard deviation below the general population (e.g., [12]) as well as their unaffected siblings [13]. A minority of individuals with NF1 show more severe intellectual deficits, with about $4-8 \%$ of individuals with NF1 meeting criteria for an intellectual disability $[10,13]$. Youth with NF1 are much more likely to develop attention deficit/hyperactivity disorder (ADHD) with rates ranging from 38 to $67 \%[13,14]$ and autism spectrum disorder (ASD) with estimates ranging from 10.0 to $39.2 \%$ using a broader phenotype $[15,16]$. Specific learning disorders, such as dyslexia, are observed in 19 to $61 \%$ youth with NF1 $[13,17]$. Difficulties with motor coordination, planning, weakness, and fatigue are also evident in NF1 [18].

Taken together, NF1 increases risk for various cognitive and neurodevelopmental outcomes. These outcomes are closely related to behavioral and social functioning which are among the strongest predictors of quality of life in NF1 [19-22]. Therefore, it is important to understand factors that contribute to these difficulties. The purpose of this paper is to examine current research on executive function (EF) in the NF1 population and how EF deficits may contribute to general and specific vulnerability for neurodevelopmental difficulties within NF1, with a focus on the clinical diagnoses of ADHD and ASD. We will also review the limitations of this approach and propose recommendations to advance clinical and translational research to improve NF1 interventions.

\section{Executive function in youth with NF1}

Executive function (EF) refers to a set of interrelated skills that are responsible for purposeful, goal-directed, problem-solving behavior [23]. EF includes initiating goal-directed behavior, inhibiting competing actions or stimuli, planning and selecting relevant task goals, organizing behavior to solve complex problems, flexible shifting of problem-solving strategies when necessary, and monitoring and evaluating problem-solving behavior ([23]; see Fig. 1c].

Extensive research has been done to try to understand the magnitude of EF deficits in NF1 and the impact such deficits have on cognition, behavior, and academic achievement. Children with NF1 have deficits in multiple EF domains when measured using daily life and laboratory measurement techniques [26]. Children and adults with NF1 exhibit extensive EF compromise in working memory capacity, inhibition, cognitive flexibility and planning [26], with effects similar to those found in ADHD and ASD samples (see Table 1). Fluency or generativity is also lower in NF1 samples [30], but it has received less attention in the NF1 literature. These EFs are thought to be primarily mediated by the prefrontal
Fig. 1 A research domain approach to characterizing behavioral and social phenotypes in NF1 across multiple levels. (a) Functional outcomes. Individuals with NF1 exhibit increased functional impairment in behavioral, social, emotional, and academic domains and, relatedly, lower quality of life. (b) Diagnosis. NF1 greatly increases the likelihood for both ADHD and ASD [4]. In the general population, genetic and phenotypic correlations between ADHD and ASD are substantive [4]. Within NF1, ADHD and ASD diagnostic categories and symptom dimensions also overlap [16]. ADHD and ASD are predictive of functional outcomes in NF1 (e.g., [24, 25]). (c) Executive functions. Working memory, inhibitory control, cognitive flexibility, and planning are interrelated executive functions [23] and reduced in NF1 [26]. EF difficulties in these domains are also associated with ADHD and ASD (Table 1) and likely contribute to common and unique risk for diagnostic and functional outcomes. (d) Neurobiology. The neurobiological underpinnings of EF and ADHD and ASD diagnoses in NF1 are just beginning to be explored. The dorsolateral prefrontal cortex, ventromedial prefrontal cortex, and the dorsal/ventral anterior cingulate cortex are consistently associated with EFs across typically and atypically developing populations. The heterogeneity in functional connectivity in NF1 in frontoparietal, frontostriatal, and ventral attention networks may alter EF profiles in NF1. (e) Genetic/Molecular/Cellular. Pathogenic variants in NF1 alter Ras signaling pathways with downstream effects on molecular and cellular phenotypes [3, 4]. Differences at this level provide a foundation for atypical neurodevelopmental trajectories

cortex (Fig. 1d; [13, 26, 31] and have been linked with academic, social and motor outcomes. The severity or variability of NF1 also needs to be considered when examining EFs in this population. For example, young patients with NF1 and an optic pathway glioma or other CNS tumors show increased EF difficulties compared to those without CNS tumors [32]. The most common EFs affected/studied in NF1 patients are discussed subsequently.

\section{NF1 and working memory}

Working memory capacity plays a fundamental role in actively holding information in the service of problem solving [23]. Working memory difficulties are evident across the life span in NF1 samples [33-35], with effect sizes in the moderate range (Table 1). Differences between working memory skills of youth with NF1 compared to controls may increase overtime [26]. A recent meta-analysis shows that verbal and visual-spatial working memory are both negatively affected in NF1, but verbal working memory may be relatively more affected [26]. However, only two included studies examined visual-spatial working memory thus results should be interpreted cautiously. In NF1, working memory plays an important role in academic outcomes [36] and may allow some to experience more benefit from educational supports like phonics-based reading intervention [37].

Evidence from both $\mathrm{NF} 1 \pm$ mice and humans indicates hypoactivation in frontoparietal and frontostriatal networks, including the dorsolateral prefrontal cortex (dIPFC), which is associated with working memory deficits in humans [38]. In 


\section{a Functional Outcomes \\ Behavioral + Social + Academic + Emotional Regulation + Quality of Life}

\section{b Diagnosis}

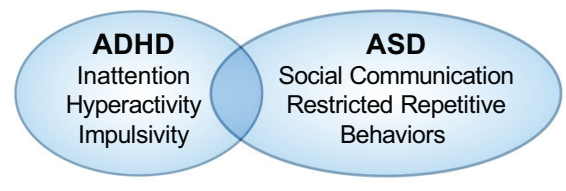

C Executive Functions

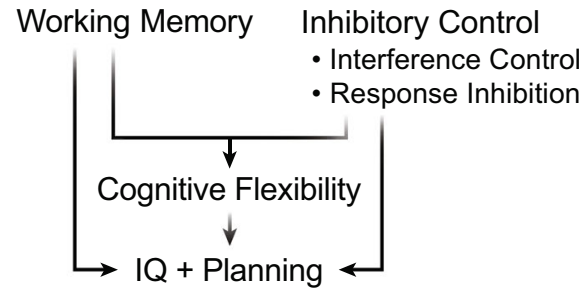

\section{d Neurobiology}

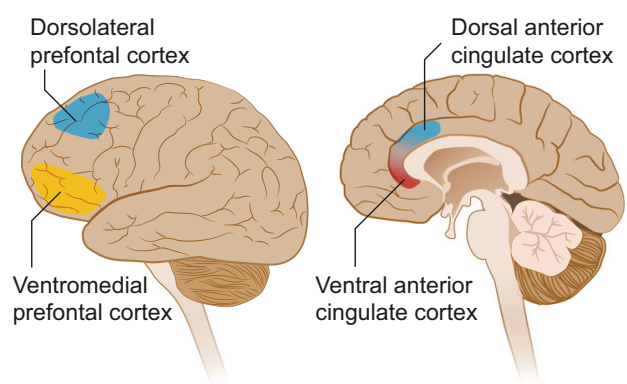

\section{e Genetic Molecular/Cellular}

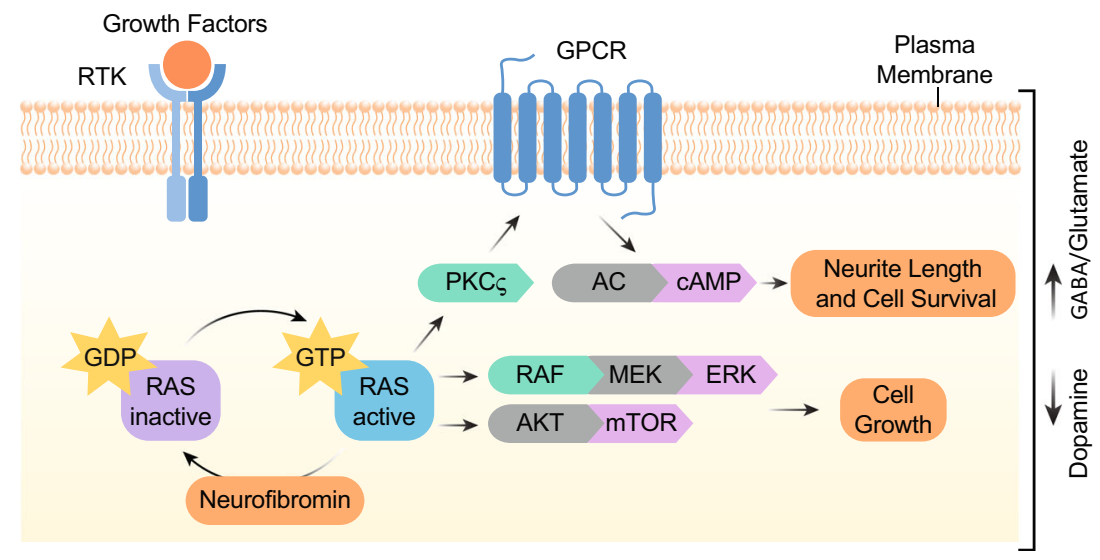

adults with NF1, there is reduced functional connectivity in the left dIPFC and the right parietal cortex [35], both implicated in the frontoparietal network. Adults with NF1 exhibit increased activation relative to controls in the posterior cingulate cortex and temporal regions [35]. Within NF1, increased connectivity between the posterior cingulate cortex and frontal and parietal cortices is associated with increased working memory performance [35]. Additionally, a pilot study found that youth with NF1 demonstrated improved performance on tasks related to attention and spatial working memory following 6-10 weeks of Cogmed - a cognitive training program [39]. Improvements in cognitive outcomes were attributed to 


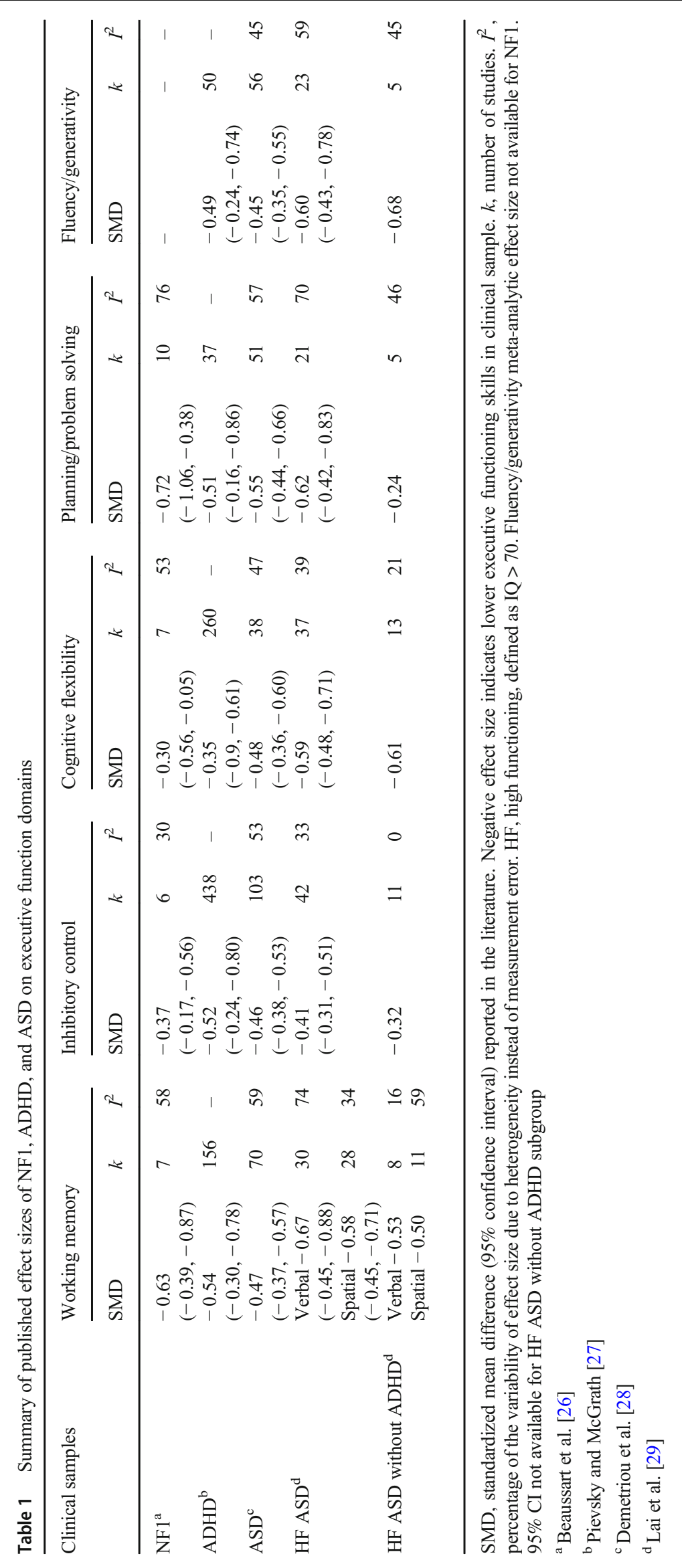


increased synchrony between the frontoparietal and visual cortex [39].

\section{NF1 and inhibitory control}

Inhibitory control works in conjunction with working memory to maintain progress towards one's goal, by sustaining focused attention and inhibiting behavioral and cognitive responses that are inconsistent with one's goal [23]. Meta-analysis indicates that individuals with NF1 have small but significant reduction in inhibitory control, relative to controls [26]. The magnitude of effect of NF1 on types of inhibitory control is similar, including interference control/cognitive inhibition, selective/focused attention, and response inhibition [26]. Inhibitory control deficits in NF1 are found in those with and without ADHD comorbidity [40]. The developmental course of deficits in inhibitory control in NF1 is not well known.

Difficulty with inhibitory responses in NF1 is associated with decreased white matter integrity within the anterior thalamic radiations within the fronto-striatal circuit [41]. In addition, NF1-related inhibitory control difficulties are associated with decreased functioning in the pre-supplementary motor area, fusiform gyrus/posterior cerebellum, and the inferior occipital gyrus [42]. Additionally, in NF1, the ventral attention network is linked with attentional control and selective attention difficulties [43]. Elevated medial frontal GABA is also associated with increased response speed in NF1 and decreased response speed in controls [44]. Altered GABA/ glutamate ratios have also been linked to NF1-related cognitive deficits [4, 45-47], and abnormal frontal GABA physiology in NF1 may be of particular importance to inhibitory control [44]. Hypofunctioning of mesolimbic dopaminergic pathways is associated with GABA/glutamate imbalance in NF1 [48]. This may contribute to differences in frontostriatal circuit function in NF1 and attentional difficulties within NF1 animal models $[49,50]$.

\section{NF1 and cognitive flexibility}

Working memory and inhibitory control contribute to cognitive flexibility which promotes switching between tasks, perspective taking, and utilizing a range of problem-solving approaches [23]. Cognitive flexibility also provides a neurocognitive foundation for creativity and theory of mind [23]. In youth with NF1, cognitive flexibility skills are lower compared to controls and the effect size is small [26]. In particular, youth with NF1 demonstrate more difficulty with reactive flexibility — or adapting problem solving behavior in the context of inconsistent environmental responses [51]. These differences are related to ASD-associated behaviors [30]. Deficits in cognitive flexibility remain after controlling for IQ [51] and spatial working memory and inhibition [30], indicating the deficits in cognitive flexibility in NF1 are not merely a function of other related EF weaknesses [30]. To our knowledge, no studies have investigated the neurobiological origins of cognitive flexibility specifically in NF1.

\section{NF1 and planning and problem solving}

Higher-order EF processes, like planning and problem solving, are influenced by working memory, inhibitory control, and cognitive flexibility [23]. Planning is a complex construct and includes the ability to think ahead and consider consequences of actions or the sequencing of steps to accomplish a goal [52]. Planning and problem-solving skills are significantly lower in youth with NF1 relative to controls and in the moderate range (Table 1), but there is significant heterogeneity in effect sizes between studies [26]. It is currently unclear which sample or methodological factors are associated with variability in effect size. Differences in planning between NF1 and controls are not solely due to cognitive flexibility, visualspatial reasoning, and/or ASD behavioral symptoms [30], suggesting deficits in planning skills are independent of other factors in NF1. Planning skills in NF1 youth may also be related to academic skills [36].

Youth with NF1 also experience difficulty with motor planning, motor coordination, and reduced muscle strength and fatigue [53-55]. EF planning deficits are associated with laboratory measures of motor planning [54], thus weaknesses in EF planning may contribute to motor difficulties observed in this population or vice versa. The impact of how motor deficits and cognitive skills influence one another on tasks that need a mediated motor output is not well understood in NF1. However, motor impact in NF development and cognition is beyond the scope of this paper.

Across a range of non-NF1 samples, planning appears to be a bilateral process involving the dIPFC, frontal eye fields, supplementary motor area, precuneus, caudate and anterior insula, and inferior parietal cortex [56], which have been implicated in other EFs within NF1 samples.

\section{Summary of executive functions in NF1}

Taken together, specific EF deficits in NF1 are present across the lifespan. Deficits in working memory and planning/ problem solving are in the moderate range, whereas deficits in inhibitory control and cognitive flexibility are slightly smaller (Table 1). Frontoparietal, frontostriatal, and ventral attention networks are implicated in the neural pathways mediating EF networks in NF1; however, research investigating the neural correlates of specific EFs in NF1 has been largely limited to the working memory $[35,38]$ and inhibitory control domains [41-43]. EF difficulties in NF1 are associated with decreased academic [36], motor [54], and social functioning 
[30]. Comparing EF outcomes between NF1, ADHD, and ASD samples may be the first step to increase our understanding of common and unique neurocognitive risk in NF1. However, to guide diagnosis and treatment, EFs should be integrated in a multi-level phenotypic characterization from genomics and circuits to behavior and self-reports, in order to explore basic dimensions of functioning.

\section{Executive functions in ADHD and ASD in the general population}

Both ADHD and ASD are considered neurodevelopmental disorders with onset in childhood, and although causal links are currently unknown, both disorders are highly heritable with approximately $64-91 \%$ of both phenotypes being accounted for by genetics [57, 58]. ADHD and ASD symptom dimensions are correlated at both a phenotypic and genetic level [4]. Genetic correlations between ADHD and ASD symptom dimensions range from 0.33 to $0.56[59,60]$.

ADHD is characterized by elevated levels of inattention and/or hyperactivity/impulsivity in comparison to same-aged peers [61]. EF deficits largely contribute to the ADHD behavioral phenotype [62-64]. Relative to controls, individuals with ADHD demonstrate weaknesses in working memory, response inhibition, sustained attention, cognitive flexibility, planning, and fluency/generativity [27, 65]. However, the severity of EF deficits in ADHD varies by age and type of assessment $[65,66]$.

Alterations in the fronto-dorsal striatal network are related to disruptions in the mesocortical dopaminergic pathway [67, 68]. Additionally, altered reward circuitry, which is linked to the mesolimbic dopaminergic pathway, is associated with delay aversion contributing to impulsivity, inattention, or hyperactivity, depending on context $[67,68]$. EF deficits in ADHD youth are related to hypoactivation in the frontoparietal and ventral attention networks, with increased activation also observed in the default, ventral attention, and somatomotor networks $[69,70]$.

ASD is characterized by social communication difficulties and restricted interests/repetitive behaviors. ASD is a highly heterogeneous disorder in symptom presentation and severity level. However, EF deficits in ASD are common and include weaknesses in working memory, inhibitory control, cognitive flexibility, planning, fluency, and concept formation [28], with effects in the moderate range across EF domains (Table 1). EF deficits in ASD appear to be largely stable across development [28], observed in individuals with ASD without intellectual disability [29, 71, 72], and are negatively associated with quality of life [73]. Additionally, variation in EF skills account for some phenotypic heterogeneity within ASD, including in social functioning [74], restricted interests/ repetitive behaviors [75], disruptive behavior [71], and theory of mind [76]. Approximately $28 \%$ of individuals with ASD also experience comorbid ADHD, among other comorbid disorders which are associated with EF impairments [77].

Data from a pooled resting-state fMRI analysis indicates that individuals with ASD exhibit corticocortical and interhemispheric functional hypoconnectivity, as well as hyperconnectivity in local subcortical circuits [78]. This indicates that during EF tasks individuals with ASD may prioritize the engagement of subcortical local circuits over long-range circuits [79]. Increased hyperconnectivity in ASD is associated with greater impairment [80]. Additionally, hypoconnectivity within frontoparietal and ventral attention networks is associated with ADHD symptoms in ASD [81].

\section{ADHD and ASD in NF1: the role of executive function}

From a clinical perspective, it is clear that EF deficits are central to the comorbidity between NF1 and neurodevelopmental outcomes that affect quality of life. EF impact is not specific to academic performance but spans multiple domains of functioning (Fig. 1), from social interaction to economic independence. Traditional clinical assessments often measure EF functioning to inform diagnostic clarification, often related to ADHD, ASD or learning disabilities. While this categorical approach helps patients and families to access services and remediation interventions, it provides very little information about neuroscience and the neurobiological underpinnings of these manifestations. However, as this approach is the one that is currently used, we will summarize the findings from the limited studies examining EF deficits in patients with NF1 and ADHD and or ASD symptomatology.

\section{NF1 and ADHD}

In the NF1 population, ADHD diagnosis has been reported to be between 38 and 67\% [13,14]. Those individuals are expected to have a more complex profile of $\mathrm{EF}$ and attention deficits than do the NF1 patients without an ADHD diagnosis. In addition, the presence of ADHD has been found to be a major risk factor for poor social functioning [11, 25, 82], as well as poor general intellectual functioning [14, 83]. Although there is evidence that cognitive control deficits are not limited to NF1 patients with comorbid ADHD [40, 84], children with both disorders are acknowledged as among the most severely affected in terms of academic performance, social interactions, and behavioral problems $[11,14,25]$.

Children with NF1 with concomitant diagnosis of ADHD experience significant deficits in visual and verbal working memory [85]. Working memory is a particularly compelling target for intervention, given its critical role in the development of most cognitive and academic outcomes. In healthy 
children, it has been suggested that developmental increases in IQ are associated with age-related improvements in working memory and processing speed [86]. Because working memory capacity increases two- to three-fold from age 4 to 16 [87], disruption of the development of these processes can significantly curtail a wide range of the child's abilities over time. This may take the form of diminished IQ or difficulty with other aspects of EF and academic performance. For example, children with reading difficulties frequently have deficits in working memory that appear to contribute to problems with phonological memory [88, 89]. Math skills are also strongly linked to working memory capacity in typically developing children accounting for $20-57 \%$ of the variance in math performance $[88,90]$.

From a developmental perspective, it is reasonable to hypothesize that improving working memory in children with NF1 may help to offset problems with IQ, EF, and academic performance over time. Computerized working memory training interventions that have been tested on multiple neurological conditions to increase working memory are currently being tested on patients with NF1 [91]. If proven beneficial, these interventions may be used during the developmental periods to improve working memory, and have downstream effects on cognitive domains and functioning across domains. Assessment and interventions targeting improvements in EF should include patients from pre-school age to early adulthood given findings that EF deficits persist into adulthood in NF1 $[25,34,82]$.

\section{NF1 and ASD}

Parent and teacher report indicate that children with NF1 exhibit significant social functioning difficulties. They are perceived as socially isolated or sensitive as well as displaying less leadership behaviors $[11,16,92]$. Youth with NF1 show higher levels of autistic traits or meet full diagnostic criteria of ASD $[15,16]$. For example, $44 \%$ of an NF1 sample demonstrated restricted and repetitive behaviors at least one standard deviation above the mean [11]. Additionally, problems with flexibility, transitions, and manifestations [92]. Impairment in social communication and lack of motivation in social interactions are reported in at least $30 \%$ of these children. From a neuropsychological perspective, these symptoms may be due to the complex dysfunction of frontal lobe pathways and EF alterations [93]. It is clear that ASD diagnosis in NF1 is not a homogenous profile and may differ significantly from ASD expression in non-NF1 samples.

The International NF1-ASD Consortium Team (INFACT) was created to further understand the significantly elevated rates of ASD symptomatology seen in NF1 samples. A multi-site analysis of 531 individuals with NF1 found that patients exhibited a significant burden of autistic traits and symptoms along a continuous distribution that encompassed the full range of severity, from mild (subclinical) to severe (clinical) [16]. The consortium sample confirmed that more than $13.2 \%$ presented with severe symptoms of ASD and more than $43.2 \%$ were above the threshold scores for an ASD diagnosis. When NF1 was inherited, there was a high degree of within family association for the severity of autistic traits. Research into the biological mechanisms impacting these social deficits is currently on-going [47, 94].

The characterization of the behavioral and cognitive phenotype, genetic correlations and potential translation into therapeutics is an essential next step for the NF1 population. Of special interest is improving our understanding of cognitive flexibility - a key EF component. Difficulty with cognitive flexibility is also observed in NF1-related comorbidities, like ASD $[95,96]$ and anxiety [97, 98]. Difficulties with cognitive flexibility may contribute to increased externalizing and internalizing behavior $[99,100]$, especially in the context of parental inconsistency [101]. Thus, the interaction between cognitive flexibility and inconsistent contingency management in the environment may be one pathway to increased behavioral or emotional dysregulation in the NF1 population.

In summary, current advances in our understanding of increased rates of ASD symptomatology in patients with NF1 have demonstrated that the association between the syndromes is real and most likely associated at the genetic level. However, we have only taken the first steps into a completely novel field that has the potential to yield an abundance of research possibilities. By analyzing phenotypes and genetic correlations and weighing potential pharmacological and non-pharmacological interventions, we can continue to explore this relationship and the correlations with other genetic conditions as well.

\section{Discussion}

The goal of this paper is to examine the impact that EFs have on the profile of neurodevelopmental outcomes in patients with NF1. At a group level, EF difficulties in NF1 are diffuse across EF domains, with moderate deficits in working memory and planning/problem solving domains and smaller deficits in inhibitory control and cognitive flexibility domains [26]. Evidence from NF1 human and animal studies implicates frontoparietal and frontostriatal circuitry working memory functioning $[35,38,39]$ and frontostriatal and ventral attention circuits in inhibitory control functioning [41-43]. EFs serve as a putative mechanism underlying the relationship between NF1 and ADHD and NF1 and ASD and allow us to understand variability in ADHD and ASD within the NF1 population.

It is essential that we advance our understanding of the neurobiological variability of neural pathways, molecular and genetic factors that impact NF1. This will improve our 
ability to develop targeted molecular interventions for cognitive deficits in this population. However, doing so requires a shift away from using a categorical framework for ASD and ADHD diagnosis and towards a detailed phenotypic evaluation (neuropsychological testing plus behavioral scales) in conjunction with objective neuro-biological assessments (i.e., fMRI, resting state fMRI, and genetic pathways; [102]).

Limitations and future directions for research First, differences in EF measurement between studies and limited reliability of single EF domain measures limit our ability to compare and replicate findings. The neurocognitive committee of the Response Evaluation in Neurofibromatosis and Schwannomatosis (REiNS) International Collaboration has provided guidance on measurement within the domain of attention [103] which should support measurement consistency between studies. Additionally, a latent factor approach with multiple indicators of EF domains will aid in the reduction of measurement error and improve replicability across studies [104]. Second, the majority of EF and cognitive research in NF1 is from case-control designs and analyses within NF1 samples are limited by sample size. These group-based EF differences may not apply to individual-level data, which limit their utility in understanding how to tailor intervention to individual NF1 cases. More analysis examining EF profiles or clusters within NF1 and linking these across multiple levels (e.g., neurofunctional and behavioral) are needed [24, 105]. Larger sample sizes and multidimensional and multidisciplinary research approaches need be strongly supported [8]. Third, neurobiological studies of EF in NF1 are limited to working memory and inhibitory control/attentional domains. The field would benefit from studies to extend our understanding of which neural circuits underpin EF cognitive flexibility, planning, and fluency/generativity domains. Important efforts are being made to improve our understanding of the neurobiological underpinnings of psychiatric and cognitive conditions $[102,106]$.

Implications of multilevel phenotyping A multi-level characterization of EF in NF1 (see Fig. 1) will help to provide an understanding of targets for interventions and ways to tailor intervention to individual cases. EFs may provide a general target to improve behavioral, social and academic functioning in the NF1 population. Given high prevalence rates of multiple neurodevelopmental disorders in NF1 and their comorbidity, EF provides a common or shared vulnerability target, which may help to maximize improvement across multiple domains of functioning.

Significant advances in the understanding of functional neural circuits implicated in brain function in patients with NF1 have been made. Using resting state fMRI, small studies have shown an overall decrease of the short and long-distance connectivity in the default network in patients with NF1 compared with typically developing controls [107]. In addition, changes in brain connectivity were observed after 12 weeks of treatment with lovastatin [107] and after computer training intervention for working memory [39]. A recent translational research study comparing brain functional connectivity in animal models of NF1 and patients with diagnosis of NF1 showed that decreased connectivity using resting state fMRI is a feature that is present in animals and patients carrying the NF1 mutations [108]. Additionally, the biological correlation between NF1 animal models and humans can be used to advance testing for medications and other interventions into clinical trials. However, correlations with high order cognitive function may require better phenotyping into complex models that allow understanding from the molecular pathway to the clinical manifestations.

Taken together, EF difficulties play an important role in the overall cognitive difficulties in NF1 and a core role in the social and behavioral profiles in this population; however, they are not fully understood [30]. We need to better understand the impact of EF deficits on these neurodevelopmental outcomes in individuals with NF1 beyond current DSM categorical diagnosis. As we better understand the neurobiology of EFs in individuals who are typically developing and those with developmental and neurodevelopmental disorders, we can better translate our knowledge to specific neurogenetic disorders like NF1.

Funding information Intramural program NIH/NHGRI/OCD to MTA. Cal Poly CLA Summer Research Stipend to TFS.

\section{Compliance with ethical standards}

Conflict of interest Not applicable.

\section{References}

1. Evans DG, Howard E, Giblin C, Clancy T, Spencer H, Huson SM, Lalloo F (2010) Birth incidence and prevalence of tumor-prone syndromes: estimates from a UK family genetic register service. Am J Med Genet A 152A:327-332. https://doi.org/10.1002/ajmg. a.33139

2. Neurofibromatosis (1987) Natl inst health consens dev conf consens statement, vol 6, pp 1-7

3. Gutmann DH, Ferner RE, Listernick RH, Korf BR, Wolters PL, Johnson KJ (2017) Neurofibromatosis type 1. Nat Rev Dis Primers 3:17004. https://doi.org/10.1038/nrdp.2017.4

4. Kaczorowski JA, Smith TF, Shrewsbury AM, Thomas LR, Knopik VS, Acosta MT (2020) Neurofibromatosis type 1 implicates Ras pathways in the genetic architecture of neurodevelopmental disorders. Behav Genet. https://doi.org/10. 1007/s10519-020-09991-x

5. Selumetinib Shrinks Tumors in Neurofibromatosis (2020) Cancer Discov. https://doi.org/10.1158/2159-8290.CD-NB2020-025

6. Uthoff J, Larson J, Sato TS, Hammond E, Schroeder KE, Rohret F, Rogers CS, Quelle DE, Darbro BW, Khanna R, Weimer JM, Meyerholz DK, Sieren JC (2020) Longitudinal phenotype 
development in a minipig model of neurofibromatosis type 1 . Sci Rep 10:5046. https://doi.org/10.1038/s41598-020-61251-4

7. White KA, Swier VJ, Cain JT, Kohlmeyer JL, Meyerholz DK, Tanas MR, Uthoff J, Hammond E, Li H, Rohret FA, Goeken A, Chan $\mathrm{CH}$, Leidinger MR, Umesalma S, Wallace MR, Dodd RD, Panzer K, Tang AH, Darbro BW, Moutal A, Cai S, Li W, Bellampalli SS, Khanna R, Rogers CS, Sieren JC, Quelle DE, Weimer JM (2018) A porcine model of neurofibromatosis type 1 that mimics the human disease. JCI Insight 3. https://doi.org/10. 1172/jci.insight. 120402

8. Acosta MT, Bearden CE, Castellanos FX, Cutting L, Elgersma Y, Gioia G, Gutmann DH, Lee YS, Legius E, Muenke M, North K, Parada LF, Ratner N, Hunter-Schaedle K, Silva AJ (2012) The learning disabilities network (LeaDNet): using neurofibromatosis type 1 (NF1) as a paradigm for translational research. Am J Med Genet A 158A:2225-2232. https://doi.org/10.1002/ajmg.a.35535

9. Torres Nupan MM, Velez Van Meerbeke A, Lopez Cabra CA, Herrera Gomez PM (2017) Cognitive and behavioral disorders in children with neurofibromatosis type 1. Front Pediatr 5:227. https://doi.org/10.3389/fped.2017.00227

10. Vogel AC, Gutmann DH, Morris SM (2017) Neurodevelopmental disorders in children with neurofibromatosis type 1. Dev Med Child Neurol 59:1112-1116. https://doi.org/10.1111/dmen.13526

11. Walsh KS, Velez JI, Kardel PG, Imas DM, Muenke M, Packer RJ, Castellanos FX, Acosta MT (2013) Symptomatology of autism spectrum disorder in a population with neurofibromatosis type 1 . Dev Med Child Neurol 55:131-138. https://doi.org/10.1111/ dmcn. 12038

12. Cutting LE, Levine TM (2010) Cognitive profile of children with neurofibromatosis and reading disabilities. Child Neuropsychol 16:417-432. https://doi.org/10.1080/09297041003761985

13. Hyman SL, Shores A, North KN (2005) The nature and frequency of cognitive deficits in children with neurofibromatosis type 1 . Neurology 65:1037-1044. https://doi.org/10.1212/01.wnl. 0000179303.72345.ce

14. Lidzba K, Granstrom S, Lindenau J, Mautner VF (2012) The adverse influence of attention-deficit disorder with or without hyperactivity on cognition in neurofibromatosis type 1. Dev Med Child Neurol 54:892-897. https://doi.org/10.1111/j.1469-8749. 2012.04377.x

15. Eijk S, Mous SE, Dieleman GC, Dierckx B, Rietman AB, de Nijs PFA, Ten Hoopen LW, van Minkelen R, Elgersma Y, CatsmanBerrevoets CE, Oostenbrink R, Legerstee JS (2018) Autism spectrum disorder in an unselected cohort of children with neurofibromatosis type 1 (NF1). J Autism Dev Disord 48:2278-2285. https://doi.org/10.1007/s10803-018-3478-0

16. Morris SM, Acosta MT, Garg S, Green J, Huson S, Legius E, North KN, Payne JM, Plasschaert E, Frazier TW, Weiss LA, Zhang Y, Gutmann DH, Constantino JN (2016) Disease burden and symptom structure of autism in neurofibromatosis type 1: a study of the international NF1-ASD consortium team (INFACT). JAMA Psychiatry 73:1276-1284. https://doi.org/10.1001/ jamapsychiatry.2016.2600

17. North KN, Riccardi V, Samango-Sprouse C, Ferner R, Moore B, Legius E, Ratner N, Denckla MB (1997) Cognitive function and academic performance in neurofibromatosis. 1: Consensus statement from the NF1 Cognitive Disorders Task Force. Neurology 48:1121-1127. https://doi.org/10.1212/wnl.48.4.1121

18. Summers MA, Quinlan KG, Payne JM, Little DG, North KN, Schindeler A (2015) Skeletal muscle and motor deficits in neurofibromatosis type 1. J Musculoskelet Neuronal Interact 15:161170

19. Garwood MM, Bernacki JM, Fine KM, Hainsworth KR, Davies WH, Klein-Tasman BP (2012) Physical, cognitive, and psychosocial predictors of functional disability and health-related quality of life in adolescents with neurofibromatosis-1. Pain Res Treat 2012: 975364. https://doi.org/10.1155/2012/975364

20. Payne JM, Haebich KM, MacKenzie R, Walsh KS, Hearps SJC, Coghill D, Barton B, Pride NA, Ullrich NJ, Tonsgard JH, Viskochil D, Schorry EK, Klesse L, Fisher MJ, Gutmann DH, Rosser T, Packer RJ, Korf B, Acosta MT, Bellgrove MA, North KN (2019) Cognition, ADHD symptoms, and functional impairment in children and adolescents with neurofibromatosis type 1. J Atten Disord:1087054719894384. https://doi.org/10.1177/ 1087054719894384

21. Wolkenstein P, Rodriguez D, Ferkal S, Gravier H, Buret V, Algans N, Simeoni MC, Bastuji-Garin S (2009) Impact of neurofibromatosis 1 upon quality of life in childhood: a cross-sectional study of 79 cases. Br J Dermatol 160:844-848. https://doi.org/10. 1111/j.1365-2133.2008.08949.x

22. Wolters PL, Burns KM, Martin S, Baldwin A, Dombi E, ToledoTamula MA, Dudley WN, Gillespie A, Widemann BC (2015) Pain interference in youth with neurofibromatosis type 1 and plexiform neurofibromas and relation to disease severity, socialemotional functioning, and quality of life. Am J Med Genet A 167A:2103-2113. https://doi.org/10.1002/ajmg.a.37123

23. Diamond A (2013) Executive functions. Annu Rev Psychol 64: 135-168. https://doi.org/10.1146/annurev-psych-113011-143750

24. Eby NS, Griffith JL, Gutmann DH, Morris SM (2019) Adaptive functioning in children with neurofibromatosis type 1: relationship to cognition, behavior, and magnetic resonance imaging. Dev Med Child Neurol 61:972-978. https://doi.org/10.1111/dmen.14144

25. Mautner VF, Granstrom S, Leark RA (2015) Impact of ADHD in adults with neurofibromatosis type 1: associated psychological and social problems. J Atten Disord 19:35-43. https://doi.org/10. $1177 / 1087054712450749$

26. Beaussart ML, Barbarot S, Mauger C, Roy A (2018) Systematic review and meta-analysis of executive functions in preschool and school-age children with neurofibromatosis type 1 . J Int Neuropsychol Soc 24:977-994. https://doi.org/10.1017/ S1355617718000383

27. Pievsky MA, McGrath RE (2018) The neurocognitive profile of attention-deficit/hyperactivity disorder: a review of meta-analyses. Arch Clin Neuropsychol 33:143-157. https://doi.org/10.1093/ $\operatorname{arclin} / \mathrm{acx} 055$

28. Demetriou EA, Lampit A, Quintana DS, Naismith SL, Song YJC, Pye JE, Hickie I, Guastella AJ (2018) Autism spectrum disorders: a meta-analysis of executive function. Mol Psychiatry 23:11981204. https://doi.org/10.1038/mp.2017.75

29. Lai CLE, Lau Z, Lui SSY, Lok E, Tam V, Chan Q, Cheng KM, Lam SM, Cheung EFC (2017) Meta-analysis of neuropsychological measures of executive functioning in children and adolescents with high-functioning autism spectrum disorder. Autism Res 10: 911-939. https://doi.org/10.1002/aur.1723

30. Plasschaert E, Van Eylen L, Descheemaeker MJ, Noens I, Legius E, Steyaert J (2016) Executive functioning deficits in children with neurofibromatosis type 1: the influence of intellectual and social functioning. Am J Med Genet B Neuropsychiatr Genet 171B: 348-362. https://doi.org/10.1002/ajmg.b.32414

31. Payne JM, Hyman SL, Shores EA, North KN (2011) Assessment of executive function and attention in children with neurofibromatosis type 1: relationships between cognitive measures and realworld behavior. Child Neuropsychol 17:313-329. https://doi.org/ 10.1080/09297049.2010.542746

32. Taddei M, Erbetta A, Esposito S, Saletti V, Bulgheroni S, Riva D (2019) Brain tumors in NF1 children: influence on neurocognitive and behavioral outcome. Cancers (Basel) 11. https://doi.org/10. 3390/cancers 11111772

33. Casnar CL, Klein-Tasman BP (2017) Parent and teacher perspectives on emerging executive functioning in preschoolers with neurofibromatosis type 1: comparison to unaffected children and lab- 
based measures. J Pediatr Psychol 42:198-207. https://doi.org/10. 1093/jpepsy/jsw042

34. Costa Dde S, de Paula JJ, de Rezende NA, Rodrigues LO, MalloyDiniz LF, Romano-Silva MA, Miranda DM (2014) Neuropsychological impairments in elderly neurofibromatosis type 1 patients. Eur J Med Genet 57:216-219. https://doi.org/10. 1016/j.ejmg.2014.02.004

35. Ibrahim AFA, Montojo CA, Haut KM, Karlsgodt KH, Hansen L, Congdon E, Rosser T, Bilder RM, Silva AJ, Bearden CE (2017) Spatial working memory in neurofibromatosis 1: altered neural activity and functional connectivity. Neuroimage Clin 15:801811. https://doi.org/10.1016/j.nicl.2017.06.032

36. Gilboa Y, Rosenblum S, Fattal-Valevski A, Toledano-Alhadef H, Josman N (2014) Is there a relationship between executive functions and academic success in children with neurofibromatosis type 1? Neuropsychol Rehabil 24:918-935. https://doi.org/10. 1080/09602011.2014.920262

37. Arnold SS, Barton B, McArthur G, North KN, Payne JM (2016) Phonics training improves reading in children with neurofibromatosis type 1: a prospective intervention trial. J Pediatr 177:219226 e212. https://doi.org/10.1016/j.jpeds.2016.06.037

38. Shilyansky C, Karlsgodt KH, Cummings DM, Sidiropoulou K, Hardt M, James AS, Ehninger D, Bearden CE, Poirazi P, Jentsch JD, Cannon TD, Levine MS, Silva AJ (2010) Neurofibromin regulates corticostriatal inhibitory networks during working memory performance. Proc Natl Acad Sci U S A 107: 13141-13146. https://doi.org/10.1073/pnas.1004829107

39. Yoncheva YN, Hardy KK, Lurie DJ, Somandepalli K, Yang L, Vezina G, Kadom N, Packer RJ, Milham MP, Castellanos FX, Acosta MT (2017) Computerized cognitive training for children with neurofibromatosis type 1: a pilot resting-state fMRI study. Psychiatry Res Neuroimaging 266:53-58. https://doi.org/10. 1016/j.pscychresns.2017.06.003

40. Huijbregts S, Swaab H, de Sonneville L (2010) Cognitive and motor control in neurofibromatosis type I: influence of maturation and hyperactivity-inattention. Dev Neuropsychol 35:737-751. https://doi.org/10.1080/87565641.2010.508670

41. Koini M, Rombouts S, Veer IM, Van Buchem MA, Huijbregts SCJ (2017) White matter microstructure of patients with neurofibromatosis type 1 and its relation to inhibitory control. Brain Imaging Behav 11:1731-1740. https://doi.org/10.1007/s11682016-9641-3

42. Pride NA, Korgaonkar MS, North KN, Barton B, Payne JM (2017) The neural basis of deficient response inhibition in children with neurofibromatosis type 1: evidence from a functional MRI study. Cortex 93:1-11. https://doi.org/10.1016/j.cortex.2017.04. 022

43. Pride NA, Korgaonkar MS, North KN, Payne JM (2018) Impaired engagement of the ventral attention system in neurofibromatosis type 1. Brain Imaging Behav 12:499-508. https://doi.org/10. 1007/s11682-017-9717-8

44. Ribeiro MJ, Violante IR, Bernardino I, Edden RA, CasteloBranco M (2015) Abnormal relationship between GABA, neurophysiology and impulsive behavior in neurofibromatosis type 1 . Cortex 64:194-208. https://doi.org/10.1016/j.cortex.2014.10.019

45. Costa RM, Federov NB, Kogan JH, Murphy GG, Stern J, Ohno M, Kucherlapati R, Jacks T, Silva AJ (2002) Mechanism for the learning deficits in a mouse model of neurofibromatosis type 1 . Nature 415:526-530. https://doi.org/10.1038/nature711

46. Cui Y, Costa RM, Murphy GG, Elgersma Y, Zhu Y, Gutmann DH, Parada LF, Mody I, Silva AJ (2008) Neurofibromin regulation of ERK signaling modulates GABA release and learning. Cell 135:549-560. https://doi.org/10.1016/j.cell.2008.09.060

47. Goncalves J, Violante IR, Sereno J, Leitao RA, Cai Y, Abrunhosa A, Silva AP, Silva AJ, Castelo-Branco M (2017) Testing the excitation/inhibition imbalance hypothesis in a mouse model of the autism spectrum disorder: in vivo neurospectroscopy and molecular evidence for regional phenotypes. Mol Autism 8:47. https://doi.org/10.1186/s13229-017-0166-4

48. Robinson JE, Coughlin GM, Hori AM, Cho JR, Mackey ED, Turan Z, Patriarchi T, Tian L, Gradinaru V (2019) Optical dopamine monitoring with dLight1 reveals mesolimbic phenotypes in a mouse model of neurofibromatosis type 1. Elife 8 . https://doi.org/ 10.7554/eLife.48983

49. Brown JA, Emnett RJ, White CR, Yuede CM, Conyers SB, O'Malley KL, Wozniak DF, Gutmann DH (2010) Reduced striatal dopamine underlies the attention system dysfunction in neurofibromatosis-1 mutant mice. Hum Mol Genet 19:45154528. https://doi.org/10.1093/hmg/ddq382

50. Diggs-Andrews KA, Gutmann DH (2013) Modeling cognitive dysfunction in neurofibromatosis-1. Trends Neurosci 36:237247. https://doi.org/10.1016/j.tins.2012.12.002

51. Roy A, Barbarot S, Roulin JL, Charbonnier V, Fasotti L, Stalder JF, Le Gall D (2014) Is executive function specifically impaired in children with neurofibromatosis type 1? A neuropsychological investigation of cognitive flexibility. Appl Neuropsychol Child 3:94-102. https://doi.org/10.1080/21622965.2012.704185

52. Rowe JB, Owen AM, Johnsrude IS, Passingham RE (2001) Imaging the mental components of a planning task. Neuropsychologia 39:315-327. https://doi.org/10.1016/s00283932(00)00109-3

53. Cornett KM, North KN, Rose KJ, Burns J (2015) Muscle weakness in children with neurofibromatosis type 1. Dev Med Child Neurol 57:733-736. https://doi.org/10.1111/dmcn.12777

54. Remigereau C, Roy A, Costini O, Barbarot S, Bru M, Le Gall D (2018) Praxis skills and executive function in children with neurofibromatosis type 1. Appl Neuropsychol Child 7:224-234. https://doi.org/10.1080/21622965.2017.1295856

55. Vassallo G, Mughal Z, Robinson L, Weisberg D, Roberts SA, Hupton E, Eelloo J, Burkitt Wright EM, Garg S, Lewis L, Evans DG, Stivaros SM (2020) Perceived fatigue in children and young adults with neurofibromatosis type 1 . J Paediatr Child Health. https://doi.org/10.1111/jpc.14764

56. Nitschke K, Kostering L, Finkel L, Weiller C, Kaller CP (2017) A meta-analysis on the neural basis of planning: activation likelihood estimation of functional brain imaging results in the Tower of London task. Hum Brain Mapp 38:396-413. https://doi.org/10. 1002/hbm. 23368

57. Faraone SV, Larsson H (2019) Genetics of attention deficit hyperactivity disorder. Mol Psychiatry 24:562-575. https://doi.org/10. 1038/s41380-018-0070-0

58. Tick B, Bolton P, Happe F, Rutter M, Rijsdijk F (2016) Heritability of autism spectrum disorders: a meta-analysis of twin studies. J Child Psychol Psychiatry 57:585-595. https://doi.org/ 10.1111/jcpp. 12499

59. Ghirardi L, Pettersson E, Taylor MJ, Freitag CM, Franke B, Asherson P, Larsson H, Kuja-Halkola R (2019) Genetic and environmental contribution to the overlap between ADHD and ASD trait dimensions in young adults: a twin study. Psychol Med 49: 1713-1721. https://doi.org/10.1017/S003329171800243X

60. Pinto R, Rijsdijk F, Ronald A, Asherson P, Kuntsi J (2016) The genetic overlap of attention-deficit/hyperactivity disorder and autistic-like traits: an investigation of individual symptom scales and cognitive markers. J Abnorm Child Psychol 44:335-345. https://doi.org/10.1007/s10802-015-0037-4

61. Association AP (2013) Diagnostic and statistical manual of mental disorders, 5th edn Washington, DC

62. Barkley RA (1997) Behavioral inhibition, sustained attention, and executive functions: constructing a unifying theory of ADHD. Psychol Bull 121:65-94. https://doi.org/10.1037/0033-2909.121. 1.65 
63. Mueller A, Hong DS, Shepard S, Moore T (2017) Linking ADHD to the neural circuitry of attention. Trends Cogn Sci 21:474-488. https://doi.org/10.1016/j.tics.2017.03.009

64. Salum GA, Sonuga-Barke E, Sergeant J, Vandekerckhove J, Gadelha A, Moriyama TS, Graeff-Martins AS, Manfro GG, Polanczyk G, Rohde LA (2014) Mechanisms underpinning inattention and hyperactivity: neurocognitive support for ADHD dimensionality. Psychol Med 44:3189-3201. https://doi.org/10. 1017/S0033291714000919

65. Willcutt EG, Doyle AE, Nigg JT, Faraone SV, Pennington BF (2005) Validity of the executive function theory of attention-deficit/hyperactivity disorder: a meta-analytic review. Biol Psychiatry 57:1336-1346. https://doi.org/10.1016/j.biopsych.2005.02.006

66. Isquith PK, Roth RM, Gioia G (2013) Contribution of rating scales to the assessment of executive functions. Appl Neuropsychol Child 2:125-132. https://doi.org/10.1080/ 21622965.2013.748389

67. Sagvolden T, Johansen EB, Aase H, Russell VA (2005) A dynamic developmental theory of attention-deficit/hyperactivity disorder (ADHD) predominantly hyperactive/impulsive and combined subtypes. Behav Brain Sci 28:397-419; discussion 419-368. https://doi.org/10.1017/S0140525X05000075

68. Sonuga-Barke EJ (2003) The dual pathway model of AD/HD: an elaboration of neuro-developmental characteristics. Neurosci Biobehav Rev 27:593-604. https://doi.org/10.1016/j.neubiorev. 2003.08.005

69. Cortese S, Kelly C, Chabernaud C, Proal E, Di Martino A, Milham MP, Castellanos FX (2012) Toward systems neuroscience of ADHD: a meta-analysis of 55 fMRI studies. Am J Psychiatry 169:1038-1055. https://doi.org/10.1176/appi.ajp.2012.11101521

70. Faraone SV, Asherson P, Banaschewski T, Biederman J, Buitelaar JK, Ramos-Quiroga JA, Rohde LA, Sonuga-Barke EJ, Tannock R, Franke B (2015) Attention-deficit/hyperactivity disorder. Nat Rev Dis Prim 1:15020. https://doi.org/10.1038/nrdp.2015.20

71. Maddox BB, Cleary P, Kuschner ES, Miller JS, Armour AC, Guy L, Kenworthy L, Schultz RT, Yerys BE (2018) Lagging skills contribute to challenging behaviors in children with autism spectrum disorder without intellectual disability. Autism 22:898-906. https://doi.org/10.1177/1362361317712651

72. Rosello B, Berenguer C, Baixauli I, Colomer C, Miranda A (2018) ADHD symptoms and learning behaviors in children with ASD without intellectual disability. A mediation analysis of executive functions. PLoS One 13:e0207286. https://doi.org/10.1371/ journal.pone.0207286

73. de Vries M, Geurts H (2015) Influence of autism traits and executive functioning on quality of life in children with an autism spectrum disorder. J Autism Dev Disord 45:2734-2743. https:// doi.org/10.1007/s10803-015-2438-1

74. Leung RC, Vogan VM, Powell TL, Anagnostou E, Taylor MJ (2016) The role of executive functions in social impairment in autism spectrum disorder. Child Neuropsychol 22:336-344. https://doi.org/10.1080/09297049.2015.1005066

75. Mostert-Kerckhoffs MA, Staal WG, Houben RH, de Jonge MV (2015) Stop and change: inhibition and flexibility skills are related to repetitive behavior in children and young adults with autism spectrum disorders. J Autism Dev Disord 45:3148-3158. https:// doi.org/10.1007/s10803-015-2473-y

76. Pellicano E (2007) Links between theory of mind and executive function in young children with autism: clues to developmental primacy. Dev Psychol 43:974-990. https://doi.org/10.1037/00121649.43.4.974

77. Lai MC, Kassee C, Besney R, Bonato S, Hull L, Mandy W, Szatmari P, Ameis SH (2019) Prevalence of co-occurring mental health diagnoses in the autism population: a systematic review and meta-analysis. Lancet Psychiatry 6:819-829. https://doi.org/10. 1016/S2215-0366(19)30289-5
78. Di Martino A, Yan CG, Li Q, Denio E, Castellanos FX, Alaerts K, Anderson JS, Assaf M, Bookheimer SY, Dapretto M, Deen B, Delmonte S, Dinstein I, Ertl-Wagner B, Fair DA, Gallagher L, Kennedy DP, Keown CL, Keysers C, Lainhart JE, Lord C, Luna B, Menon V, Minshew NJ, Monk CS, Mueller S, Muller RA, Nebel MB, Nigg JT, O'Hearn K, Pelphrey KA, Peltier SJ, Rudie JD, Sunaert S, Thioux M, Tyszka JM, Uddin LQ, Verhoeven JS, Wenderoth N, Wiggins JL, Mostofsky SH, Milham MP (2014) The autism brain imaging data exchange: towards a large-scale evaluation of the intrinsic brain architecture in autism. Mol Psychiatry 19:659-667. https://doi.org/10.1038/mp.2013.78

79. Muhle RA, Reed HE, Stratigos KA, Veenstra-VanderWeele J (2018) The emerging clinical neuroscience of autism spectrum disorder: a review. JAMA Psychiatry 75:514-523. https://doi. org/10.1001/jamapsychiatry.2017.4685

80. Holiga S, Hipp JF, Chatham CH, Garces P, Spooren W, D'Ardhuy XL, Bertolino A, Bouquet C, Buitelaar JK, Bours C, Rausch A, Oldehinkel M, Bouvard M, Amestoy A, Caralp M, Gueguen S, Ly-Le Moal M, Houenou J, Beckmann CF, Loth E, Murphy D, Charman T, Tillmann J, Laidi C, Delorme R, Beggiato A, Gaman A, Scheid I, Leboyer M, d'Albis MA, Sevigny J, Czech C, Bolognani F, Honey GD, Dukart J (2019) Patients with autism spectrum disorders display reproducible functional connectivity alterations. Sci Transl Med 11. https://doi.org/10.1126/ scitranslmed.aat9223

81. Yerys BE, Tunc B, Satterthwaite TD, Antezana L, Mosner MG, Bertollo JR, Guy L, Schultz RT, Herrington JD (2019) Functional connectivity of frontoparietal and salience/ventral attention networks have independent associations with co-occurring attention-deficit/hyperactivity disorder symptoms in children with autism. Biol Psychiatry Cogn Neurosci Neuroimaging 4:343-351. https://doi.org/10.1016/j.bpsc.2018.12.012

82. Pride NA, Crawford H, Payne JM, North KN (2013) Social functioning in adults with neurofibromatosis type 1. Res Dev Disabil 34:3393-3399. https://doi.org/10.1016/j.ridd.2013.07.011

83. Koth CW, Cutting LE, Denckla MB (2000) The association of neurofibromatosis type 1 and attention deficit hyperactivity disorder. Child Neuropsychol 6:185-194. https://doi.org/10.1076/chin. 6.3.185.3155

84. Lehtonen A, Howie E, Trump D, Huson SM (2013) Behaviour in children with neurofibromatosis type 1: cognition, executive function, attention, emotion, and social competence. Dev Med Child Neurol 55:111-125. https://doi.org/10.1111/j.1469-8749.2012. 04399.x

85. Payne JM, Arnold SS, Pride NA, North KN (2012) Does attention-deficit-hyperactivity disorder exacerbate executive dysfunction in children with neurofibromatosis type 1? Dev Med Child Neurol 54:898-904. https://doi.org/10.1111/j.1469-8749. 2012.04357.x

86. Fry AF, Hale S (2000) Relationships among processing speed, working memory, and fluid intelligence in children. Biol Psychol 54:1-34. https://doi.org/10.1016/s0301-0511(00)00051-x

87. Gathercole SE (1999) Cognitive approaches to the development of short-term memory. Trends Cogn Sci 3:410-419. https://doi.org/ 10.1016/s1364-6613(99)01388-1

88. Rennie B, Beebe-Frankenberger M, Swanson HL (2014) A longitudinal study of neuropsychological functioning and academic achievement in children with and without signs of attention-deficit/hyperactivity disorder. J Clin Exp Neuropsychol 36:621-635. https://doi.org/10.1080/13803395.2014.921284

89. Swanson HL, Howard CB, Saez L (2006) Do different components of working memory underlie different subgroups of reading disabilities? J Learn Disabil 39:252-269. https://doi.org/10.1177/ 00222194060390030501

90. Zheng X, Swanson HL, Marcoulides GA (2011) Working memory components as predictors of children's mathematical word 
problem solving. J Exp Child Psychol 110:481-498. https://doi. org/10.1016/j.jecp.2011.06.001

91. Hardy KK (2020) Efficacy of computerized cognitive training and stimulant medication in neurofibromatosis type 1 (COGTRAIN). https://clinicaltrials.gov/ct2/show/NCT02944032

92. Garg S, Lehtonen A, Huson SM, Emsley R, Trump D, Evans DG, Green J (2013) Autism and other psychiatric comorbidity in neurofibromatosis type 1: evidence from a population-based study. Dev Med Child Neurol 55:139-145. https://doi.org/10.1111/ dmen. 12043

93. Hartman CA, Geurts HM, Franke B, Buitelaar JK, Rommelse NNJ (2016) Changing ASD-ADHD symptom co-occurrence across the lifespan with adolescence as crucial time window: illustrating the need to go beyond childhood. Neurosci Biobehav Rev 71:529-541. https://doi.org/10.1016/j.neubiorev.2016.09. 003

94. Maloney SE, Chandler KC, Anastasaki C, Rieger MA, Gutmann DH, Dougherty JD (2018) Characterization of early communicative behavior in mouse models of neurofibromatosis type 1 . Autism Res 11:44-58. https://doi.org/10.1002/aur.1853

95. Gioia GA, Isquith PK, Kenworthy L, Barton RM (2002) Profiles of everyday executive function in acquired and developmental disorders. Child Neuropsychol 8:121-137. https://doi.org/10. 1076/chin.8.2.121.8727

96. Rosenthal M, Wallace GL, Lawson R, Wills MC, Dixon E, Yerys BE, Kenworthy L (2013) Impairments in real-world executive function increase from childhood to adolescence in autism spectrum disorders. Neuropsychology 27:13-18. https://doi.org/10. 1037/a0031299

97. Lawson RA, Papadakis AA, Higginson CI, Barnett JE, Wills MC, Strang JF, Wallace GL, Kenworthy L (2015) Everyday executive function impairments predict comorbid psychopathology in autism spectrum and attention deficit hyperactivity disorders. Neuropsychology 29:445-453. https://doi.org/10.1037/ neu0000145

98. Wilson CG, Nusbaum AT, Whitney P, Hinson JM (2018) Trait anxiety impairs cognitive flexibility when overcoming a task acquired response and a preexisting bias. PLoS One 13:e0204694. https://doi.org/10.1371/journal.pone.0204694

99. Burrows CA, Timpano KR, Uddin LQ (2017) Putative brain networks underlying repetitive negative thinking and comorbid internalizing problems in autism. Clin Psychol Sci 5:522-536. https:// doi.org/10.1177/2167702616683506

100. Schoemaker K, Mulder H, Dekovic M, Matthys W (2013) Executive functions in preschool children with externalizing behavior problems: a meta-analysis. J Abnorm Child Psychol 41: 457-471. https://doi.org/10.1007/s10802-012-9684-x

101. Sosic-Vasic Z, Kroner J, Schneider S, Vasic N, Spitzer M, Streb J (2017) The association between parenting behavior and executive functioning in children and young adolescents. Front Psychol 8: 472. https://doi.org/10.3389/fpsyg.2017.00472

102. Sanislow CA, Ferrante M, Pacheco J, Rudorfer MV, Morris SE (2019) Advancing translational research using NIMH research domain criteria and computational methods. Neuron 101:779782. https://doi.org/10.1016/j.neuron.2019.02.024

103. Walsh KS, Janusz J, Wolters PL, Martin S, Klein-Tasman BP, Toledo-Tamula MA, Thompson HL, Payne JM, Hardy KK, de Blank P, Semerjian C, Gray LS, Solomon SE, Ullrich N, Collaboration REI (2016) Neurocognitive outcomes in neurofibromatosis clinical trials: recommendations for the domain of attention. Neurology 87:S21-S30. https://doi.org/10.1212/WNL. 0000000000002928

104. Payne JM, Hearps SJC, Walsh KS, Paltin I, Barton B, Ullrich NJ, Haebich KM, Coghill D, Gioia GA, Cantor A, Cutter G, Tonsgard JH, Viskochil D, Rey-Casserly C, Schorry EK, Ackerson JD, Klesse L, Fisher MJ, Gutmann DH, Rosser T, Packer RJ, Korf B, Acosta MT, North KN, Consortium NFCT (2019) Reproducibility of cognitive endpoints in clinical trials: lessons from neurofibromatosis type 1. Ann Clin Transl Neurol 6:25552565. https://doi.org/10.1002/acn3.50952

105. Vaidya CJ, You X, Mostofsky S, Pereira F, Berl MM, Kenworthy L (2020) Data-driven identification of subtypes of executive function across typical development, attention deficit hyperactivity disorder, and autism spectrum disorders. J Child Psychol Psychiatry 61:51-61. https://doi.org/10.1111/jcpp.13114

106. Sanders SJ, Sahin M, Hostyk J, Thurm A, Jacquemont S, Avillach P, Douard E, Martin CL, Modi ME, Moreno-De-Luca A, Raznahan A, Anticevic A, Dolmetsch R, Feng G, Geschwind DH, Glahn DC, Goldstein DB, Ledbetter DH, Mulle JG, Pasca SP, Samaco R, Sebat J, Pariser A, Lehner T, Gur RE, Bearden CE (2019) A framework for the investigation of rare genetic disorders in neuropsychiatry. Nat Med 25:1477-1487. https://doi.org/10. 1038/s41591-019-0581-5

107. Chabernaud C, Mennes M, Kardel PG, Gaillard WD, Kalbfleisch ML, Vanmeter JW, Packer RJ, Milham MP, Castellanos FX, Acosta MT (2012) Lovastatin regulates brain spontaneous lowfrequency brain activity in neurofibromatosis type 1 . Neurosci Lett 515:28-33. https://doi.org/10.1016/j.neulet.2012.03.009

108. Shofty B, Bergmann E, Zur G, Asleh J, Bosak N, Kavushansky A, Castellanos FX, Ben-Sira L, Packer RJ, Vezina GL, Constantini S, Acosta MT, Kahn I (2019) Autism-associated Nfl deficiency disrupts corticocortical and corticostriatal functional connectivity in human and mouse. Neurobiol Dis 130:104479. https://doi.org/10. 1016/j.nbd.2019.104479 